\title{
Article \\ Changes in Tobacco Use Patterns during COVID-19 and Their Correlates among Older Adults in Bangladesh
}

\author{
Sabuj Kanti Mistry 1,2,3,*(D), Armm Mehrab Ali 1,4(D), Md. Ashfikur Rahman ${ }^{5}\left(\mathbb{D}\right.$, Uday Narayan Yadav ${ }^{2,6,7}$, \\ Bhawna Gupta ${ }^{7}$, Muhammad Aziz Rahman ${ }^{8,9,+}$ (D) and Rumana Huque $10,11,+$
}

1 Department of Health Research, ARCED Foundation, 13/1, Pallabi, Mirpur-12, Dhaka 1216, Bangladesh; mehrabbabu@gmail.com

2 Centre for Primary Health Care and Equity, University of New South Wales, Sydney, NSW 2052, Australia; unyadav1@gmail.com

3 BRAC James P Grant School of Public Health, BRAC University, 68 Shahid Tajuddin Ahmed Sharani, Mohakhali, Dhaka 1212, Bangladesh

4 Global Research and Data Support, Innovations for Poverty Action, 101 Whitney Avenue, New Haven, CT 06510, USA

5 Development Studies Discipline, Khulna University, Khulna 9208, Bangladesh; ashfikur@ku.ac.bd

6 Center for Research, Policy and Implementation, Biratnagar 56613, Nepal

7 Department of Public Health, Torrens University, Melbourne, VIC 3000, Australia; bhawna.gupta@laureate.edu.au

8 School of Health, Federation University Australia, Berwick, VIC 3806, Australia; ma.rahman@federation.edu.au

9 Australian Institute of Primary Care and Ageing, La Trobe University, Melbourne, VIC 3086, Australia

10 Department of Economics, University of Dhaka, Dhaka 1000, Bangladesh; rumanah14@yahoo.com

check for

updates

Citation: Mistry, S.K.; Ali, A.M.; Rahman, M..A.; Yadav, U.N.; Gupta,

B.; Rahman, M.A.; Huque, R.

Changes in Tobacco Use Patterns during COVID-19 and Their Correlates among Older Adults in Bangladesh. Int. J. Environ. Res. Public Health 2021, 18, 1779. https:// doi.org/ 10.3390/ijerph18041779

Academic Editor: Scott Weaver Received: 30 December 2020

Accepted: 9 February 2021

Published: 12 February 2021

Publisher's Note: MDPI stays neutral with regard to jurisdictional claims in published maps and institutional affiliations.

Copyright: (c) 2021 by the authors. Licensee MDPI, Basel, Switzerland This article is an open access article distributed under the terms and conditions of the Creative Commons Attribution (CC BY) license (https:// creativecommons.org/licenses/by/ $4.0 /)$
11 Research and Development, ARK Foundation, Gulshan, Dhaka 1212, Bangladesh

* Correspondence: smitra411@gmail.com; Tel.: +61-40-6863358

+ Equal contributor.

Abstract: The present study explored the changes in tobacco use patterns during the COVID-19 pandemic and their correlates among older adults in Bangladesh. This cross-sectional study was conducted among 1032 older adults aged $\geq 60$ years in Bangladesh through telephone interviews in October 2020. Participants' characteristics and COVID-19-related information were gathered using a pretested semi-structured questionnaire. Participants were asked if they noted any change in their tobacco use patterns (smoking or smokeless tobacco) during the COVID-19 pandemic compared to pre-pandemic (6 months prior to the survey). Nearly half of the participants (45.6\%) were current tobacco users, of whom $15.9 \%$ reported increased tobacco use during the COVID-19 pandemic and all others had no change in their tobacco use patterns. Tobacco use was significantly increased among the participants from rural areas, who had reduced communications during COVID-19 compared to pre-pandemic $(\mathrm{OR}=2.76,95 \% \mathrm{CI}: 1.51-5.03)$. Participants who were aged $\geq 70$ years $(\mathrm{OR}=0.33,95 \%$ CI: 0.14-0.77), widowed (OR $=0.36,95 \%$ CI: 0.13-1.00), had pre-existing, non-communicable, and/or chronic conditions ( $\mathrm{OR}=0.44,95 \% \mathrm{CI}$ : 0.25-0.78), and felt themselves at the highest risk of COVID-19 $(\mathrm{OR}=0.31,95 \% \mathrm{CI}: 0.15-0.62)$, had significantly lower odds of increased tobacco use. Policy makers and practitioners need to focus on strengthening awareness and raising initiatives to avoid tobacco use during such a crisis period.

Keywords: tobacco use; smoking; smokeless tobacco; COVID-19; Bangladesh

\section{Introduction}

Tobacco use is one of the leading causes of premature death and morbidity [1]. The World Health Organization (WHO) reported that around 1 billion people are currently smokers, of whom $80 \%$ are living in low-middle income countries (LMICs). It has been estimated that tobacco causes about $8.8 \%$ of total annual global deaths ( 4.9 million) and $4.1 \%$ of disability-adjusted life years (DALYs) (59.1 million) [2]. 
All countries globally have been affected by tobacco, but now this epidemic is shifting from high-income countries to LMICs including Bangladesh, a South Asian country, because of the international expansion of major tobacco companies [3]. Smoking tobacco and consuming smokeless tobacco (SLT) products are significant risk factors of non-communicable diseases (NCDs) [4]. A total of 126,000 deaths were caused by tobaccorelated diseases in 2018 in Bangladesh [5]. According to the most recent Global Adult Tobacco Survey, 35.3\% of adults were consuming tobacco products in Bangladesh in 2017, where the prevalence of smoking was $18.0 \%$. Notably, the smoking prevalence was considerably higher among males [6]. While people of all ages are at risk of tobacco use, the prevalence of tobacco use was the highest among older adults aged 55 years and above (64.2\%; smoking: 26.9\%; SLT: $47.1 \%$ ) in Bangladesh [7], making them at risk of tobacco-related morbidities and death.

The COVID-19 pandemic is the most remarkable public health calamity of this century. The disease continues to invade the entire world; as of 28 January 2021, there were more than 2 million deaths with more than 100 million confirmed cases worldwide. More than 533 thousand confirmed cases with 8072 deaths were also reported by the same date in Bangladesh [8]. Although everybody is at risk of COVID-19, certain groups of the population are more vulnerable than others to its deadliest effects. One such group is older adults who are particularly vulnerable to morbidity and mortality from COVID-19, as they often suffer from different non-communicable and/or chronic conditions such as diabetics, hypertension, and obesity [9-11]. Evidence suggests that hospitalisation rates are higher among older adults aged 65 years or over, and deaths are 23 times more likely compared to those aged below 65 years [12].

At the same time, the growing pandemic is augmenting existing mental health problems by exacerbating the extent of loneliness, anxiety, panic, depression, and long-term psychosocial impacts among older adults [13]. Prolonged lockdown, social distancing, and self-isolation are increasing stress and fear, with the potential upsurge of tobacco use [14]. In addition, tobacco use may increase due to its use as a coping strategy for the increasing levels of anxiety and stress exacerbated by the isolation and quarantine imposed during COVID-19 [11,15]. The diverse nexus of intertwined biological and socio-ecological factors amid this pandemic alongside the lack of access to health care services may augment the density of depression, suicide, domestic violence, and psychiatric illnesses [10], resulting in a higher use of tobacco products.

While no clear relationship has been established so far between smoking and COVID19 , evidence suggests that tobacco use increases the severity of the disease among COVID19 patients $[14,16,17]$. During the previous Middle East respiratory syndrome coronavirus (MERS-CoV) outbreak as well, smokers were twice as likely to be affected by and incur deaths from the influenza than non-smokers $[18,19]$. Therefore, the present study was carried out in Bangladesh to know about the changes in tobacco use patterns during COVID19 among older adults. The study also explored the factors associated with changes in tobacco use among older adults in Bangladesh.

\section{Materials and Methods}

\subsection{Study Design and Participants}

This cross-sectional study was conducted remotely through telephone interviews in October 2020. We utilised a pre-established registry, developed through merging the contact information of households from ten different community-based studies accomplished by Aureolin Research, Consultancy, and Expertise Development (ARCED) Foundation during 2016-2020 as sampling frame. The registry comprised almost 9000 households for which verified contact information was available. It included households from mixed demographic groups, including urban and rural areas, different income groups, and households from all eight administrative divisions of Bangladesh.

The sample size of 1096 was calculated considering a 50\% prevalence with a $5 \%$ margin of error, at the $95 \%$ level of confidence, $90 \%$ power of the test, and $95 \%$ response 
rate. However, only 1032 participants participated in the final study, with an overall response rate of approximately $94 \%$. To ensure representativeness from all divisions, we adopted a probability proportionate to the number of older adults in each division [20].

A stratified random sampling technique was followed to select the targeted households from each administrative division. One eligible respondent was interviewed from each of the sampled households. In cases where there was more than one eligible participant in a selected household, the oldest one was interviewed. Daily attempts to reach the sampled households by phone were made for up to three days. It required an average of 1.30 ( $\mathrm{SD} \pm 0.57$ ) phone calls for each participant to successfully survey the 1032 participants. In cases where any household from a certain administrative division was not possible to reach, did not fit the inclusion criteria, or refused to participate, a replacement sample was taken randomly from that specific administrative division. The inclusion criterion was being aged 60 years and above, and the exclusion criteria included severe mental health problems (clinically proved schizophrenia, bipolar mood disorder, dementia/cognitive impairment), a hearing disability, extensive memory problems resulting in the unreliability of answers, or inability to communicate.

\subsection{Measures}

\subsubsection{Outcome Measures}

The outcome variable of this study considered whether the current tobacco users (smoking any tobacco products or using any SLTs within 30 days of the survey [21]) perceived any change in their tobacco use patterns during COVID-19 compared to before the pandemic ( 6 months prior to the survey). We asked the participants if they have noted any change in their tobacco use patterns during COVID-19. We categorised and coded the outcome variables as changes in tobacco use patterns during COVID-19 $(0=$ no change, $1=$ increased). We did not find anyone who reported to decrease tobacco use during the COVID-19 pandemic; thus, this change was excluded from the coding.

\subsubsection{Explanatory Variables}

The explanatory variables considered in this study were as follows: age (categorised as 60-69, 70-79, and $\geq 80$ ); sex (male/female); marital status (married/widowed); literacy (illiterate/literate); family size $(\leq 4$ or $>4)$; family income in Bangladeshi Taka (BDT) $(<5000,5000-10,000,>10,000)$; residence (urban/rural); occupation (currently employed/unemployed or retired); living arrangements (living alone or with family); memory or concentration problems (no problem/low memory or concentration); presence of pre-existing non-communicable chronic conditions (yes/no); concerned about COVID-19 (hardly, sometimes/often); difficulty in getting food, medicine, and routine medical care during COVID-19 (yes/no); frequency of communication with friends and family during COVID-19 (less than previous/same as previous); and source of COVID-19-related information (TV/radio, health workers, and friends/family/neighbours).

Self-reported information on pre-existing medical conditions, such as arthritis, hypertension, heart diseases, stroke, hypercholesterolemia, diabetes, chronic respiratory diseases, chronic kidney disease, and cancer were also collected.

\subsubsection{Data Collection Tools and Techniques}

A validated semi-structured questionnaire in the Bengali language, in which most of the questions were adopted from previous studies, was used to collect the information [22-24]. The Bengali version of the tool was piloted among a small sample $(n=10)$ of older adults to refine the language in the final version. The participants approved the tool designed by research team without any corrections or suggestions.

Data collection was conducted through telephone interviews by 10 data collectors and the responses were noted in the SurveyCTO mobile app (Dobility, Inc., Washington, DC, USA) (https:/ /www.surveycto.com/). The data collectors were trained extensively for four days by Sabuj Kanti Mistry, ARM Mehrab Ali, and Uday Narayan Yadav remotely 
using the Zoom platform (Zoom Video Communications, Inc., San Jose, CA, USA) before the data collection.

\subsubsection{Statistical Analysis}

The distribution of the variables was assessed through descriptive analysis. Given our variables' categorical nature, Chi-square tests were performed to compare differences in the changes in tobacco use by explanatory variables, with a $5 \%$ level of significance. We used binary logistic regression models to explore the factors associated with dichotomised changes in tobacco use. The initial model was run with all potential covariates, then using the backward elimination criteria with the Akaike information criterion (AIC), a final model was selected. The adjusted odds ratio (aOR) and associated 95\% confidence interval (95\% $\mathrm{CI})$ were reported. All analyses were performed using the statistical software package Stata (Version 14.0, StataCorp LLC, Texas, TX, USA).

\subsubsection{Ethical Approval}

The study protocol was approved by the institutional review board of Institute of Health Economics, University of Dhaka, Bangladesh (Ref: IHE/2020/1037). Verbal informed consent was sought from the participants before administering the survey. Participation was voluntary, and participants did not receive any compensation.

\section{Results}

A total of 1032 older adults participated in this study, of whom 471 participants (45.6\%) were using tobacco, i.e., smokers (20.2\%), SLT users (33.1\%), and dual users $(7.7 \%)$. Of the 471 current tobacco users, $21.0 \%$ were from the Dhaka division, $77.1 \%$ aged $60-69$ years, $72.0 \%$ male, $72.0 \%$ from the rural areas, $57.5 \%$ illiterate, $82.8 \%$ were married, and $93.4 \%$ were residing with their family members. Over half of them $(61.6 \%)$ had a family income of $>10,000$ Bangladeshi Taka ( 1 Bangladeshi Taka $\approx 0.012$ USD) and resided at more than 30 min walking distance from the nearest health centre (53.1\%). Details are shown in Table 1.

Table 1. Participants' characteristics and bivariate analysis of changes in tobacco use during COVID-19.

\begin{tabular}{|c|c|c|c|c|c|}
\hline \multirow{3}{*}{ Characteristics } & \multirow{3}{*}{$\begin{array}{c}\text { Overall }(\mathrm{n}=1032) \\
\mathrm{n}(\%)\end{array}$} & \multirow{3}{*}{$\begin{array}{c}\text { Tobacco User }(n=471) \\
n(\%)\end{array}$} & \multicolumn{3}{|c|}{ Change in Tobacco Use } \\
\hline & & & No Change & \multicolumn{2}{|c|}{ Increased } \\
\hline & & & n (\%) & n (\%) & $p$ \\
\hline Overall & & & $396(84.1)$ & $75(15.9)$ & \\
\hline \multicolumn{6}{|l|}{ Division } \\
\hline Barishal & $149(14.4)$ & $62(13.2)$ & $49(79.0)$ & $13(21.0)$ & 0.556 \\
\hline Cottogram & 137(13.3) & $62(13.2)$ & $54(87.1)$ & $8(12.9)$ & \\
\hline Dhaka & $210(20.4)$ & $99(21.0)$ & $79(79.8)$ & $20(20.2)$ & \\
\hline Mymensingh & $63(6.1)$ & $25(5.3)$ & $20(80.0)$ & $5(20.0)$ & \\
\hline Khulna & $158(15.3)$ & $72(15.3)$ & $64(88.9)$ & $8(11.1)$ & \\
\hline Rajshahi & 103(10.0) & $44(9.3)$ & $36(81.8)$ & $8(18.2)$ & \\
\hline Rangpur & $144(14.0)$ & $69(14.7)$ & $61(88.4)$ & $8(11.6)$ & \\
\hline Sylhet & $68(6.6)$ & $38(8.1)$ & $33(86.8)$ & $5(13.2)$ & \\
\hline \multicolumn{6}{|l|}{ Age (year, \%) } \\
\hline $60-69$ & $803(77.8)$ & $363(77.1)$ & $297(81.8)$ & $66(18.2)$ & 0.014 \\
\hline$\geq 70$ & $229(22.2)$ & $108(22.9)$ & $99(91.7)$ & $9(8.3)$ & \\
\hline \multicolumn{6}{|l|}{ Sex } \\
\hline Male & $676(65.5)$ & $339(72.0)$ & $286(84.4)$ & $53(15.6)$ & 0.783 \\
\hline Female & $356(34.5)$ & $132(28.0)$ & $110(83.3)$ & $22(16.7)$ & \\
\hline \multicolumn{6}{|l|}{ Marital status } \\
\hline Married & $840(81.4)$ & $390(82.8)$ & $320(82.1)$ & $70(18.0)$ & 0.008 \\
\hline Widow/Widower & 192(18.6) & $81(17.2)$ & $76(93.8)$ & $5(6.2)$ & \\
\hline \multicolumn{6}{|l|}{ Literacy } \\
\hline Illiterate & $602(58.3)$ & $271(57.5)$ & $231(85.2)$ & $40(14.8)$ & 0.422 \\
\hline literate & $430(41.7)$ & $200(42.5)$ & $165(82.5)$ & $35(17.5)$ & \\
\hline
\end{tabular}


Table 1. Cont.

\begin{tabular}{|c|c|c|c|c|c|}
\hline \multirow{3}{*}{ Characteristics } & \multirow{3}{*}{$\begin{array}{c}\text { Overall }(\mathrm{n}=1032) \\
\mathrm{n}(\%)\end{array}$} & \multirow{3}{*}{$\begin{array}{c}\text { Tobacco User }(n=471) \\
n(\%)\end{array}$} & \multicolumn{3}{|c|}{ Change in Tobacco Use } \\
\hline & & & No Change & \multicolumn{2}{|c|}{ Increased } \\
\hline & & & n (\%) & n (\%) & $p$ \\
\hline \multicolumn{6}{|l|}{ Family size } \\
\hline$\leq 4$ & $318(30.8)$ & $134(28.5)$ & $115(85.8)$ & $19(14.2)$ & 0.514 \\
\hline$>4$ & $714(69.2)$ & $337(71.6)$ & $281(83.4)$ & $56(16.6)$ & \\
\hline \multicolumn{6}{|l|}{ Family income (BDT) } \\
\hline$<5000$ & $145(14.1)$ & $60(12.7)$ & $43(71.7)$ & $17(28.3)$ & 0.001 \\
\hline $5000-10,000$ & $331(32.1)$ & $121(25.7)$ & $96(79.3)$ & $25(20.7)$ & \\
\hline$>10,000$ & $556(53.9)$ & $290(61.6)$ & $257(88.6)$ & $33(11.4)$ & \\
\hline \multicolumn{6}{|l|}{ Residence } \\
\hline Urban & $269(26.1)$ & $132(28.0)$ & $124(93.9)$ & $8(6.1)$ & 0.000 \\
\hline Rural & $763(73.9)$ & $339(72.0)$ & $272(80.2)$ & $67(19.8)$ & \\
\hline \multicolumn{6}{|l|}{ Current occupation } \\
\hline Employed & $419(40.6)$ & $236(50.1)$ & $201(85.2)$ & $35(14.8)$ & 0.516 \\
\hline Unemployed & $613(59.4)$ & $235(49.9)$ & 195(83.0) & $40(17.0)$ & \\
\hline \multicolumn{6}{|l|}{ Living arrangement } \\
\hline Living with other family members & 953(92.3) & $440(93.4)$ & $372(84.6)$ & $68(15.5)$ & 0.295 \\
\hline Living alone & $79(7.7)$ & $31(6.6)$ & $24(77.4)$ & $7(22.6)$ & \\
\hline \multicolumn{6}{|l|}{ Dependent on family for living } \\
\hline No & $329(31.9)$ & $146(31.0)$ & $119(81.5)$ & $27(18.5)$ & 0.307 \\
\hline Yes & $703(68.1)$ & $325(69.0)$ & $277(85.2)$ & $48(14.8)$ & \\
\hline \multicolumn{6}{|c|}{ Walking distance to the nearest health centre } \\
\hline$<30 \mathrm{~min}$ & $508(49.2)$ & $221(46.9)$ & $183(82.8)$ & $38(17.2)$ & 0.478 \\
\hline$\geq 30 \mathrm{~min}$ & $524(50.8)$ & $250(53.1)$ & $213(85.2)$ & $37(14.8)$ & \\
\hline \multicolumn{6}{|l|}{ Problem in memory or concentration } \\
\hline No problem & $782(75.8)$ & $360(76.4)$ & $305(84.7)$ & $55(15.3)$ & 0.490 \\
\hline Low memory or concentration & $250(24.2)$ & $111(23.6)$ & $91(82.0)$ & $20(18.0)$ & \\
\hline \multicolumn{6}{|l|}{ Pre-existing chronic conditions } \\
\hline No & $424(41.1)$ & $162(34.4)$ & $122(75.3)$ & $40(24.7)$ & 0.000 \\
\hline Yes & $608(58.9)$ & $309(65.6)$ & $274(88.7)$ & $35(11.3)$ & \\
\hline \multicolumn{6}{|l|}{ Concerned about COVID-19 } \\
\hline Hardly & $299(29.0)$ & $118(25.1)$ & $99(83.9)$ & 19(16.1) & 0.951 \\
\hline Sometimes/often & $733(71.0)$ & $353(74.9)$ & $297(84.1)$ & $56(15.9)$ & \\
\hline \multicolumn{6}{|l|}{ Overwhelmed by COVID-19 } \\
\hline Hardly & $370(36.4)$ & 142(30.7) & $117(78.0)$ & $33(22.0)$ & 0.014 \\
\hline Sometimes/often & $647(63.6)$ & $321(79.3)$ & $279(86.9)$ & $42(13.1)$ & \\
\hline Feeling himself at highest risk of COVIL & & & & & \\
\hline No & $603(58.4)$ & $292(62.0)$ & $234(80.1)$ & $58(19.9)$ & 0.003 \\
\hline Yes & $429(41.6)$ & $179(38.0)$ & $162(90.5)$ & $17(9.5)$ & \\
\hline Difficulty in getting food during COVIL & & & & & \\
\hline No & $553(55.3)$ & $221(48.0)$ & $186(84.2)$ & $35(15.8)$ & 0.629 \\
\hline Yes & $447(44.7)$ & $239(52.0)$ & 205(85.8) & $34(14.2)$ & \\
\hline $\begin{array}{l}\text { Difficulty in getting medicine during } \\
\text { COVID-19 }\end{array}$ & & & & & \\
\hline No & $733(75.3)$ & $322(71.6)$ & $275(85.4)$ & $47(14.6)$ & 0.782 \\
\hline Yes & $240(24.7)$ & $128(28.4)$ & $108(84.4)$ & $20(15.6)$ & \\
\hline $\begin{array}{c}\text { Difficulty receiving routine medical ca } \\
\text { during COVID-19 }\end{array}$ & & & & & \\
\hline No & $751(72.8)$ & $311(66.0)$ & $254(81.7)$ & $57(18.3)$ & 0.047 \\
\hline Yes & $281(27.2)$ & $160(34.0)$ & $142(88.8)$ & $18(11.2)$ & \\
\hline Feeling of loneliness & & & & & \\
\hline Hardly & $822(79.7)$ & $366(77.7)$ & $301(82.2)$ & $65(17.8)$ & 0.042 \\
\hline Sometimes/often & $210(20.3)$ & $105(22.3)$ & $95(90.5)$ & $10(9.5)$ & \\
\hline $\begin{array}{l}\text { Frequency of communication during } \\
\text { COVID-19 }\end{array}$ & & & & & \\
\hline Same as previous & $598(58.0)$ & 298(63.3) & $267(89.6)$ & $31(10.4)$ & 0.000 \\
\hline Less than previous & $434(42.0)$ & $173(36.7)$ & $129(74.6)$ & $44(25.4)$ & \\
\hline Received financial support during COVI & & & & & \\
\hline No & $764(74.0)$ & $323(68.6)$ & $264(81.7)$ & $59(18.3)$ & 0.040 \\
\hline Yes & $268(26.0)$ & $148(31.4)$ & $132(89.2)$ & $16(10.8)$ & \\
\hline
\end{tabular}




\subsection{Changes in Tobacco Use during COVID-19}

The study revealed that none of the participants started tobacco use during this pandemic, and no current smokers reported a decrease in their tobacco use. However, $15.9 \%$ of the participants reported that their tobacco use had increased during COVID-19. Tobacco smoking increased among $13.5 \%$ of the participants who were current smokers, while the use of SLT products increased among $15.2 \%$ of the current SLT users. No significant difference was observed between male and female participants in terms of increased tobacco use during COVID-19. A significantly higher percentage of participants $(p<0.001)$ from rural areas reported that they had increased frequency of tobacco use during the COVID-19 pandemic compared to those from urban areas (19.8\% vs. $6.1 \%)$. Similarly, the percentage with increased tobacco use was significantly higher among the participants who had less communication with others during this pandemic than previously $(25.4 \%$ vs. $10.4 \%)$. The frequency of increased tobacco use was also significantly higher $(p<0.05)$ among participants aged 60-69 years, married, participants from poor households, those from rural areas, participants with pre-existing non-communicable chronic conditions, those who were hardly overwhelmed by COVID-19, and those who did not receive any financial support during COVID-19. See Table 1 for details.

\subsection{Factors Associated with Changed Tobacco Use during COVID-19}

In the adjusted model, age, marital status, residence, pre-existing non-communicable chronic conditions, perceived risk of COVID-19, and frequency of communication during COVID-19 as source of COVID-19-related information were all significantly associated with increased frequency of tobacco use among the participants (Table 2).

Table 2. Factors associated with increased tobacco use during COVID-19.

\begin{tabular}{|c|c|c|}
\hline Characteristics & AOR & $95 \% \mathrm{CI}$ \\
\hline \multicolumn{3}{|l|}{ Age (year, \%) } \\
\hline $60-69$ & Ref & \\
\hline$\geq 70$ & 0.33 & $0.14-0.77$ \\
\hline \multicolumn{3}{|l|}{ Marital status } \\
\hline Married & Ref & \\
\hline Widow/Widower & 0.36 & $0.13-1.00$ \\
\hline \multicolumn{3}{|l|}{ Family size } \\
\hline$\leq 4$ & Ref & \\
\hline$>4$ & 1.67 & $0.87-3.18$ \\
\hline \multicolumn{3}{|c|}{ Family monthly income (BDT) } \\
\hline$<5000$ & Ref & \\
\hline $5000-10,000$ & 0.89 & $0.37-2.15$ \\
\hline$>10,000$ & 0.69 & $0.29-1.66$ \\
\hline \multicolumn{3}{|l|}{ Residence } \\
\hline Urban & Ref & \\
\hline Rural & 2.97 & $1.27-6.94$ \\
\hline \multicolumn{3}{|l|}{ Current occupation } \\
\hline Employed & Ref & \\
\hline Unemployed or retired & 1.36 & $0.76-2.46$ \\
\hline \multicolumn{3}{|l|}{ Pre-existing conditions } \\
\hline No & Ref & \\
\hline Yes & 0.44 & $0.25-0.78$ \\
\hline \multicolumn{3}{|c|}{ Feeling themselves at the highest risk of COVID-19 } \\
\hline No & Ref & \\
\hline Yes & 0.31 & $0.15-0.62$ \\
\hline \multicolumn{3}{|c|}{ Frequency of communication during the pandemic } \\
\hline Same as previous & Ref & \\
\hline Less than previous & 2.76 & $1.51-5.03$ \\
\hline \multicolumn{3}{|c|}{ Receiving COVID-19-related information from friends/family/neighbours } \\
\hline No & Ref & \\
\hline Yes & 0.31 & $0.16-0.61$ \\
\hline
\end{tabular}

$\overline{\mathrm{AOR}}=$ Adjusted odds ratio; Note: the model was adjusted for all the variables in the table. 
We found that the participants who were aged 70 years or more had $67 \%$ lower odds of increased tobacco use than those aged 60-69 years (aOR $=0.33,95 \% \mathrm{CI}: 0.14-0.77$ ), and married participants had $64 \%$ lower odds of increased tobacco use than those who were widowed (aOR $=0.36,95 \%$ CI: 0.13-1.00). Participants residing in rural areas had nearly three times higher odds of increased tobacco use than those residing in urban areas (aOR $=2.97,95 \% \mathrm{CI}: 1.27-6.94)$, and participants who had less frequency of communication with others during the pandemic had nearly three times higher odds of increased tobacco use frequency ( $\mathrm{aOR}=2.76,95 \% \mathrm{CI}: 1.51-5.03)$. On the other hand, participants who had one or more pre-existing non-communicable chronic conditions had $56 \%$ lower odds $(\mathrm{aOR}=0.44$, 95\% CI: $0.25-0.78$ ), and those who felt themselves at the highest risk of COVID-19 had around $70 \%$ lower odds (aOR $=0.31,95 \% \mathrm{CI}$ : $0.15-0.62$ ) of increased tobacco use.

\section{Discussion}

To the best of our knowledge, this is the first study carried out among older adults in Bangladesh to explore the change in tobacco use patterns amid the COVID-19 pandemic. The present study noted an overall $15.9 \%$ rise of tobacco use in older Bangladeshi adults amid this COVID-19 pandemic. The frequency of smoking increased among $13.5 \%$ of the participants who were currently smokers, while the frequency of using smokeless tobacco products increased among $15.2 \%$ of the participants. This percentage is relatively higher compared to a recent study carried out among the adult population in Belgium, which reported that $7.5 \%$ of the participants had an increased frequency of smoking during COVID-19 [25]. Another study also explored the tobacco use patterns in five countries (Italy, India, South Africa, the United Kingdom, and the United States) during COVID-19 and noted an increased frequency of tobacco use during COVID-19 [14].

We found that a significantly higher percentage of participants from rural areas reported that they had increased tobacco use during this pandemic compared to those from urban areas. Several studies demonstrated that tobacco use is significantly higher among rural inhabitants than those of urban areas [26,27]. However, the reasons behind the increased frequency of tobacco use among rural participants compared to those in urban areas during this pandemic remain unclear. One probable reason could be that rural inhabitants were more prone to be distressed and anxious during the COVID-19 pandemic because of inadequate health care facilities, limited capabilities for public protection, and the unavailability of appropriate information [28,29], which might have led to increased tobacco use among the participants. Moreover, rural respondents are more dependent on other income-earning members who mainly work in the informal sector [30]; thus, they might have greater anxiety about future job losses of family members. This combined with the low literacy rate among older adults [31] could also lead to increased tobacco use.

Our study also demonstrated that the participants who had less frequency of communication with others during COVID-19 had the highest odds of increased tobacco use. As the present study was carried out during the peak of COVID-19 in Bangladesh, older adults having less communication with their friends and family members might have felt a loneliness that contributed to an increase in risky behaviour, such as more frequent tobacco use than that of normal times, which was also reported in several other studies [32-34]. Evidence suggests that emotions of sadness and loneliness increase the likelihood of depressive symptoms and can increase the consumption of tobacco products in the process [18]. Several other studies also documented that smoking increases with increased mental illness $[35,36]$. This is also an important finding, not only from the tobacco control policies viewpoint, but also from the health promotion perspective, as the health awareness campaigns for the current pandemic, or for any health-related issue, may not reach this group due to a lack of communication. Hence, alternate platforms such as community meetings could be a potential alternative to improve awareness in that vulnerable cohort.

Our study revealed that increase in tobacco use was significantly lower among participants aged 70 years or older compared to their younger counterparts. We also found that participants who had any pre-existing non-communicable and/or chronic conditions 
had a lower chance of increased tobacco use during the pandemic. This is possibly because relatively older participants and those who were suffering from any non-communicable and/or chronic conditions were more concerned with the deadliest effects of COVID-19 and thus had lower tobacco use. Similarly, our results also suggest that the participants who perceived that they were at the highest risk of being infected with COVID-19 had significantly lower odds of increased frequency of tobacco use. As argued previously, these participants probably became more aware of the fact that COVID-19 seriously damages the lungs with different respiratory illnesses, and tobacco use can aggravate the situation to a great extent $[10,11,14,19]$. Indeed, several studies demonstrated that tobacco use can lead to more adverse COVID-19-related outcomes than those of non-smokers [37,38], which could provide a greater motivation to decrease tobacco use. Therefore, giving up tobacco use would potentially aid efforts to tackle not only smoking-related chronic diseases, but also the new infectious-disease threat of COVID-19 [17,25]. Although a recent study argued that risky behaviour increases with increased stress related to the perceived vulnerabilities of COVID-19 [15], this was not the case in our study.

While LMICs are lagging behind in promoting tobacco control compared to developed countries, Bangladesh is one of the countries among the LMICs that has implemented tobacco control policies since 1990 [26]. This has been achieved with different measures such as banning smoking in public places and transports and banning the advertising and promotion of tobacco and tobacco product vending machines, in addition to requiring graphic warning labels on all tobacco products. The warnings provide general statements about the health consequences of tobacco use, stating that smoking causes death, lung cancer, stroke, heart disease, respiratory problems, or other problems. The text warnings cover up at least $50 \%$ of the front and back of cigarette and bidi packs [27]. In addition, the Bangladesh government initiated a policy to increase the price and taxes for all kinds of cigarettes and tobacco products, including upward adjustment tax rates [26,27]. Nevertheless, the present study revealed that the frequency of consumption of tobacco products increased significantly during the COVID-19 pandemic. Therefore, policymakers and public health professionals need to consider delivering information about risky behaviours, such as tobacco use, while disseminating the health promotion messages in Bangladesh during this crisis of COVID-19. The involvement of health workers can augment the process in this regard [39]. This study's findings and policy implications are also very relevant for other countries with similar socio-economic backgrounds.

The limitations of the study include selection bias, as the sampling frame was based on the available household-level information in our registry. Second, there are potential possibilities of recall bias, as the study participants were aged 60 years and above. Third, due to the cross-sectional design, causality cannot be established. Furthermore, a strong limitation of our study is that all the information was self-reported and was based on subjective perceptions. On the other hand, the target sample size was achieved within the period of the pandemic, which indicated a strength of this study, as we had significant power to test our hypotheses.

\section{Conclusions}

We found that tobacco use increased as a coping strategy to manage stress and anxiety among older people of $\geq 60$ years in Bangladesh amid the COVID-19 pandemic. Residing in rural areas and having less communication with others were both significant predictors for increased tobacco use in this study. Policy makers and public health practitioners need to consider strengthening awareness and raising initiatives utilising accessible channels to reach this vulnerable cohort of the population. These initiatives are needed not only to control tobacco use, but also to disseminate health awareness messages including the current regular communications about COVID-19, specifically for those living in rural areas, to help them to quit tobacco during such a pandemic. Research is also required to test the effectiveness and cost-effectiveness of such interventions. 
Author Contributions: S.K.M., A.M.A. and U.N.Y. contributed to the design of the study. S.K.M. carried out the data analysis. S.K.M., A.M.A., M.A.R. (Md. Ashfikur Rahman), and U.N.Y. contributed to writing the first draft of the manuscript. B.G., M.A.R. (Muhammad Aziz Rahman), and R.H. commented extensively on the draft of the manuscript to finalise it. All authors have read and agreed to the published version of the manuscript.

Funding: This research was not funded.

Institutional Review Board Statement: The study was conducted according to the guidelines of the Declaration of Helsinki and approved by the institutional review board of the Institute of Health Economics, University of Dhaka, Bangladesh (Ref: IHE/2020/1037).

Informed Consent Statement: Verbal informed consent was obtained from all subjects involved in the study.

Data Availability Statement: The data are available upon reasonable request from the corresponding author.

Acknowledgments: We acknowledge the role of Zahirul Islam, Sadia Sumaia Chowdhury, and Shakil Al Mamun of ARCED Foundation for their all-out support in data collection for the study.

Conflicts of Interest: The authors have no conflict of interest to disclose.

\section{References}

1. WHO. Tobacco. Available online: https://www.who.int/news-room/fact-sheets/detail/tobacco (accessed on 9 December 2020).

2. WHO. Management of Substance Abuse: Tobacco. Available online: https://www.who.int/substance_abuse/facts/tobacco/en/ (accessed on 9 December 2020).

3. Anderson, C.L.; Becher, H.; Winkler, V. Tobacco control progress in low and middle income countries in comparison to high income countries. Int. J. Environ. Res. Public Health 2016, 13, 1039. [CrossRef] [PubMed]

4. Islam, F.M.A.; Walton, A. Tobacco Smoking and Use of Smokeless Tobacco and Their Association with Psychological Distress and Other Factors in a Rural District in Bangladesh: A Cross-Sectional Study. J. Environ. Public Health 2019, 2019, 1424592. [CrossRef]

5. Burki, T.K. Tobacco consumption in Bangladesh. Lancet Oncol. 2019, 20, 478. [CrossRef]

6. WHO. Global Adult Tobacco Survey: Bangladesh Report; World Helath Organization: Dhaka, Bangladesh, 2017.

7. Nargis, N.; Thompson, M.E.; Fong, G.T.; Driezen, P.; Hussain, A.K.M.G.; Ruthbah, U.H.; Quah, A.C.K.; Abdullah, A.S. Prevalence and patterns of tobacco use in Bangladesh from 2009 to 2012: Evidence from International Tobacco Control (ITC) Study. PLoS ONE 2015, 10, e0141135. [CrossRef]

8. WHO. WHO Coronavirus Disease (COVID-19) Dashboard. Available online: https://covid19.who.int/ (accessed on 7 December 2020).

9. CDC Covid-Response Team. Severe Outcomes Among Patients with Coronavirus Disease 2019 (COVID-19)—United States, February 12-16 March 2020. MMWR Morb. Mortal. Wkly. Rep. 2020, 69, 343-346. [CrossRef]

10. Brown, E.; Gray, R.; Monaco, S.L.; O’Donoghue, B.; Nelson, B.; Thompson, A.; Francey, S.; McGorry, P. The potential impact of COVID-19 on psychosis: A rapid review of contemporary epidemic and pandemic research. Schizophr. Res. 2020, $222,79-87$. [CrossRef] [PubMed]

11. Zhao, Q.; Meng, M.; Kumar, R.; Wu, Y.; Huang, J.; Lian, N.; Deng, Y.; Lin, S. The impact of COPD and smoking history on the severity of COVID-19: A systemic review and meta-analysis. J. Med. Virol. 2020, 92, 1915-1921. [CrossRef]

12. Mueller, A.L.; McNamara, M.S.; Sinclair, D.A. Why does COVID-19 disproportionately affect older people? Aging 2020, 12, 9959-9981. [CrossRef]

13. Yadav, U.N.; Rayamajhee, B.; Mistry, S.K.; Parsekar, S.S.; Mishra, S.K. A syndemic perspective on the management of noncommunicable diseases amid the COVID-19 pandemic in low-and middle-income countries. Front. Public Health 2020, 8, 508. [CrossRef]

14. Yach, D. Tobacco use patterns in five countries during the COVID-19 Lockdown. Nicotine Tob. Res. 2020, 22, 671-1672. [CrossRef]

15. Rahman, M.A.; Hoque, N.; Alif, S.M.; Salehin, M.; Islam, S.M.S.; Banik, B.; Sharif, A.; Nazim, N.B.; Sultana, F.; Cross, W. Factors associated with psychological distress, fear and coping strategies during the COVID-19 pandemic in Australia. Glob. Health 2020, 16, 1-15. [CrossRef]

16. Alla, F.; Berlin, I.; Nguyen-Thanh, V.; Guignard, R.; Pasquereau, A.; Quelet, S.; Schwarzinger, M.; Arwidson, P. Tobacco and COVID-19: A crisis within a crisis? Can. J. Public Health 2020, 111, 995-999. [CrossRef]

17. Kalan, M.E.; Ghobadi, H.; Taleb, Z.B.; Adham, D.; Cobb, C.O.; Ward, K.D.; Behaleh, R.; Fazlzadeh, M. COVID-19 and beliefs about tobacco use: An online cross-sectional study in Iran. Environ. Sci. Pollut. Res. 2020, 1-9. [CrossRef]

18. Arcavi, L.; Benowitz, N.L. Cigarette smoking and infection. Arch. Intern. Med. 2004, 164, 2206-2216. [CrossRef]

19. Park, J.-E.; Jung, S.; Kim, A. MERS transmission and risk factors: A systematic review. BMC Public Health 2018, 18, 574. [CrossRef]

20. BBS. Elderly Population in Bangladesh: Current Features and Future Perspectives; Banglaedsh Bureau of Statistics, Ministry of Bangladesh, Government of Bangladesh: Dhaka, Bangladesh, 2015. 
21. Zaman, M.M.; Rahman, M.; Rahman, R.; Bhuiyan, M.R.; Karim, N.; Chowdhury, A.J. Prevalence of risk factors for noncommunicable diseases in Bangladesh: Results from STEPS survey 2010. Indian J. Public Health 2016, 60, 17. [CrossRef]

22. Yadav, U.N.; Tamang, M.K.; Thapa, T.B.; Hosseinzadeh, H.; Harris, M.F.; Yadav, K.K. Prevalence and determinants of frailty in the absence of disability among older population: A cross sectional study from rural communities in Nepal. BMC Geriatr. 2019, 19, 283. [CrossRef]

23. Yadav, U.N.; Thapa, T.B.; Mistry, S.K.; Pokhrel, R.; Harris, M.F. Socio-demographic characteristics, lifestyle factors, multi-morbid conditions and depressive symptoms among Nepalese older adults. BMC Psychiatry 2020, 20, 1-9. [CrossRef]

24. Khanam, F.; Hossain, M.B.; Mistry, S.K.; Afsana, K.; Rahman, M. Prevalence and risk factors of cardiovascular diseases among Bangladeshi adults: Findings from a cross-sectional study. J. Epidemiol. Glob. Health 2019, 9, 176-184. [CrossRef] [PubMed]

25. Vanderbruggen, N.; Matthys, F.; Van Laere, S.; Zeeuws, D.; Santermans, L.; Van den Ameele, S.; Crunelle, C.L. Self-reported alcohol, tobacco, and Cannabis use during COVID-19 lockdown measures: Results from a web-based survey. Eur. Addict. Res. 2020, 26, 309-315. [CrossRef]

26. Połtyn-Zaradna, K.; Zatońska, K.; Basiak, A.; Sozańska, B.; Gaweł-Dabrowska, D.; Wołyniec, M.; Szuba, A.; Zatoński, W. Sociodemographic characteristic of changes in smoking patterns in rural and urban population of PURE Poland study: Findings from 6-year follow up. BMC Public Health 2019, 19, 6. [CrossRef]

27. Buettner-Schmidt, K.; Miller, D.R.; Maack, B. Disparities in rural tobacco use, smoke-free policies, and tobacco taxes. West. J. Nurs. Res. 2019, 41, 1184-1202. [CrossRef]

28. Zhang, Y.; Chen, Y.; Wang, J.; Deng, Y.; Peng, D.; Zhao, L. Anxiety Status and Influencing Factors of Rural Residents in Hunan with Corona Virus Disease 2019: A web-based cross-sectional survey. Front. Psychiatry 2020, 11, 1319. [CrossRef]

29. Xiong, J.; Lipsitz, O.; Nasri, F.; Lui, L.M.W.; Gill, H.; Phan, L.; Chen-Li, D.; Iacobucci, M.; Ho, R.; Majeed, A. Impact of COVID-19 pandemic on mental health in the general population: A systematic review. J. Affect. Disord. 2020, 277, 55-64. [CrossRef] [PubMed]

30. Schneider, P.; Hung, A.L.; Sembera, J.; Silva-Martinez, R.D. The role of the informal sector in a rurbanized environment. In Solid Waste Management in Rural Areas; Intech Open: London, UK, 2017; pp. 27-52.

31. Rana, A.K.M.M.; Wahlin, Å.; Lundborg, C.S.; Kabir, Z.N. Impact of health education on health-related quality of life among elderly persons: Results from a community-based intervention study in rural Bangladesh. Health Promot. Int. 2009, 24, 36-45. [CrossRef]

32. Zhou, Z.; Chen, P.; Peng, H. Are healthy smokers really healthy? Tob. Induc. Dis. 2016, 14, 35. [CrossRef]

33. Gupta, R.; Dhamija, R.K. Covid-19: Social distancing or social isolation? BMJ 2020, 369, m2399. [CrossRef] [PubMed]

34. Philip, K.E.J.; Polkey, M.I.; Hopkinson, N.S.; Steptoe, A.; Fancourt, D. Social isolation, loneliness and physical performance in older-adults: Fixed effects analyses of a cohort study. Sci. Rep. 2020, 10, 13908. [CrossRef]

35. Lasser, K.; Boyd, J.W.; Woolhandler, S.; Himmelstein, D.U.; McCormick, D.; Bor, D.H. Smoking and mental illness: A populationbased prevalence study. JAMA 2000, 284, 2606-2610. [CrossRef] [PubMed]

36. DeWall, C.N.; Pond, R.S., Jr. Loneliness and smoking: The costs of the desire to reconnect. Self Identity 2011, 10, 375-385. [CrossRef]

37. Simons, D.; Shahab, L.; Brown, J.; Perski, O. The association of smoking status with SARS-CoV-2 infection, hospitalization and mortality from COVID-19: A living rapid evidence review with Bayesian meta-analyses (version 7). Addiction 2020. [CrossRef] [PubMed]

38. Vardavas, C.I.; Nikitara, K. COVID-19 and smoking: A systematic review of the evidence. Tob. Induc. Dis. 2020, 18, 20. [CrossRef]

39. Ballard, M.; Bancroft, E.; Nesbit, J.; Johnson, A.; Holeman, I.; Foth, J.; Rogers, D.; Yang, J.; Nardella, J.; Olsen, H. Prioritising the role of community health workers in the COVID-19 response. BMJ Glob. Health 2020, 5, e002550. [CrossRef] 